\title{
Development of Subacute and Complex Care Programs at the Community Level
}

\author{
Ronald Lagoe $^{1 *}$, Cheryl Noetscher ${ }^{2}$, Shelly Littau ${ }^{1}$ \\ ${ }^{1}$ Hospital Executive Council, Syracuse, USA \\ ${ }^{2}$ St. Joseph's Hospital Health Center, Syracuse, USA \\ Email: *Hospexcl@cnymail.com
}

How to cite this paper: Lagoe, R., Noetscher, C. and Littau, S. (2016) Development of Subacute and Complex Care Programs at the Community Level. Open Journal of Nursing, 6, 937-947.

http://dx.doi.org/10.4236/ojn.2016.611090

Received: October 11, 2016

Accepted: November 21, 2016

Published: November 24, 2016

Copyright $\odot 2016$ by authors and Scientific Research Publishing Inc. This work is licensed under the Creative Commons Attribution International License (CC BY 4.0).

http://creativecommons.org/licenses/by/4.0/ (c) (i) Open Access

\begin{abstract}
Patients requiring Subacute and Complex Care services continue to challenge hospitals attempting to reduce inpatient stays and improve efficiency. In recent years, numbers of high severity of illness patients in hospitals have increased, adding to this challenge. Nurse care managers have a major responsibility for supporting the care of these patients. This study described the development of services for Subacute and Complex Care patients in the hospitals of Syracuse, New York. These hospitals used their own resources to develop programs including high cost medications, intravenous therapy, extensive wound care, and bariatric care in settings where they had not been available. In the absence of third party funding of another level of care, the hospitals provided program development funds for limited time periods in order to initiate these services. The Syracuse hospitals were able to phase out support for these programs after they were operational in the nursing homes for an extended period of time. The study data indicated that implementation of these programs limited the rate of increase of adult medicine stays and reduced adult surgery stays. The severity of illness for both major services increased in the Syracuse hospitals during this time. This process required acute and long term care providers who were interested in making the process work for the benefit of the patient populations involved, as well as for the needs of their own organizations.
\end{abstract}

\section{Keywords}

Hospital Lengths of Stay, Hospitalization, Long Term Care

\section{Introduction}

Transitions from acute to lower levels of care have always been a challenge. The ability to move patients from acute care to home, assisted living, skilled nursing, or other care 
locations has become increasingly important as more patients crowd hospital emergency departments and require acute care admission. This need for movement of patients is essential to the provision of good patient care. It has been supported by both providers and payors of care [1] [2] [3].

In hospitals and health care systems, the role of the nurse care manager has taken on greater importance in moving patients between levels of care. This is a major responsibility to patients and to provider organizations.

Providers such as acute hospitals need efficiency in the delivery of care because extended stays detract from the quality of care and result in large additional expenditures for increased labor, room and board, pharmaceutical, and other costs. Reimbursement for inpatient hospital care from payors is based on discharges and does not include separate additional payments for many of these expenses [4].

The impact of these issues related to hospital lengths of stay has been heightened by risk sharing programs such as Medicare's Merit Incentive Payment System, Accountable Care Organizations and the Blue Cross ACQA Initiative. These efforts focus on efficiency in the delivery of care for hospitals and health care networks. Because of their connection to ambulatory care, many of these efforts relate directly to hospital utilization [5] [6] [7].

The implementation of bundling programs by Medicare has stimulated health care providers to improve care by reducing hospital stays and expediting discharges home. These programs began with orthopedic procedures, but are expanding to medical diagnoses [8]. In most facilities, every episode is being scrutinized to assure that all care is provided in the appropriate setting in a timely, efficient manner. Patients remaining in a hospital longer than necessary risk infections such as pneumonia, loss of mobility, skin breakdown, and other complications. Payors are assessing financial penalties when these adverse outcomes occur in an effort to stimulate providers to improve quality [9] [10] [11] [12].

Transitions from acute care require that lower intensity services are available in the community where the patient may need them. For example, patients requiring several weeks of intravenous antibiotic therapy may not require acute care but may require a skilled nursing facility employing a staff who are qualified to administer and monitor the antibiotic.

The reduction of extended hospital stays has been addressed by the development of Long Term Acute Care Programs in some states. In states where these programs have not been implemented, hospitals have developed their own initiatives to address extended stays [13] [14].

\section{Population}

This study describes the efforts of the hospitals in the metropolitan area of Syracuse, New York, to support transitions from acute care. These hospitals comprise the acute care system of the area. At the time of initiation, these less intense services were not available in nursing homes resulting in disruption of patient flow, backups in emer- 
gency departments, and staff frustrations.

The acute care facilities involved in these efforts included Crouse Hospital $(19,919$ inpatient discharges, January-December 2015), St. Joseph's Hospital Health Center (25,532 discharges, January-December 2015), and Upstate University Hospital (26,649 discharges, January-December 2015). Each of these hospitals is a large urban acute care facility that provides primary, secondary, and tertiary services. These hospitals provide acute care to a service area of 600,000 and referral center services to the eleven county Central New York Health Service Area with a population of 1,400,000.

Historically, the Syracuse hospitals have worked cooperatively to improve the efficiency of care in the local acute care system. Prior to the development of the Subacute and Complex Care Programs, cooperative programs including length of stay reduction, clinical pathways and protocols had been initiated with the nursing care management departments in conjunction with the Hospital Executive Council [15].

Additional impetus for the Subacute and Complex Care Programs occurred because the hospitals owned only 14 percent of the long term care beds in the community and New York State does not have a program that provides additional financial support for long term acute care patients [16].

\section{Method}

Beginning in 2004, the Syracuse hospitals developed a number of Subacute Programs to support the movement of patients from hospitals to nursing homes. Each of these programs focused on the development of a single service. In 2004, none of the nursing homes in the Syracuse metropolitan area provided these services.

Prior to the start of each initial program, teams of nursing staff from the hospitals worked with each participating nursing home to develop policies and procedures. Education of the nursing home staffs also occurred, assuring safe transitions for patients and alleviating concerns of hospital physicians and staff.

Individual Subacute Programs included the following.

- Intravenous Medications (2004) - including single, low cost medications such as Ceftriaxone and Vancomycin.

- High Cost Oral Medications (2005) such as Abilify and Aranesp.

- Enhanced Medications (2007) - including higher cost oral and intravenous medications such as Procrit, Penicillin G (IV), and some Chemotherapy.

- Extensive Wound Care (2005) - including use of vacuum assisted closure device equipment and special dressings.

- Bariatric (2007) - including patients with high Body Mass Indices requiring bariatric beds, lifts, wheelchairs and dedicated staff.

- Offsite Transport (2007) -including stretcher and wheelchair transportation for dialysis and other services.

In addition, the following programs were initiated in 2014 and 2015 to meet the needs of patients who required Complex Care Services.

- Multiple Intravenous Antibiotics. 
- Combinations of Medications such as antibiotics and Lovenox.

- Extensive Wound Care including vacuum assisted equipment and intravenous medications.

- Behavioral Issues Requiring One on One Care.

The Subacute and Complex Care Programs were implemented through agreements including the Syracuse hospitals, participating nursing homes, and the Hospital Executive Council. Those agreements included the following components.

1) Certification by an Access Coordinator at each hospital that the need for the program was the barrier to the discharge of each patient.

2) A community wide pool of funding.

3) Distribution of Program Development Funds for specific types of care by the Hospital Executive Council.

It was intended that Program Development Funds should support the development of these services in nursing homes, rather than being an indefinite source of funding. For this reason, the funding was phased out as nursing homes implemented most of the services.

The study was carried out using patient specific data from each of the hospitals by the Hospital Executive Council. These data were obtained through Business Associate Agreements with each of the hospitals. The Council functions as a mechanism for the development of multihospital studies in the Syracuse metropolitan area.

The study data included quantitative information concerning utilization of the Subacute and Complex Care Programs and their impact on hospital lengths of stay. These data were collected from the Hospital Executive Council which coordinated the operation of the programs.

The study data also included narrative descriptions concerning the implementation and operation of the programs in area nursing homes. This information is summarized for individual programs in the Results section. The initial component of the study focused on use of the Subacute Programs between 2008 and 2016. It included data concerning numbers of patients using each program in the combined Syracuse hospitals between 2008 and 2016. It also included information concerning experiences with the programs in participating nursing homes.

The second component of the study focused on the use of Complex Care Programs in nursing homes between 2014 and 2016. It included numbers of patients using the programs by six month period during 2015 and 2016. It also included information concerning the operation of these programs in the nursing homes.

The third component of the study evaluated inpatient lengths of stay in the combined Syracuse hospitals between 2008 and 2016, the period when the Subacute and Complex Care programs were implemented. It focused on adult medicine and adult surgery including length of stay data and severity adjusted comparisons for each service.

\section{Results}

Data concerning the initial component of the study, including utilization of the Sub- 
acute Programs in the Syracuse area, are summarized in Table 1. Related information also includes descriptions of the implementation and operation of the programs.

The initial Subacute Program developed by the Syracuse hospitals and area nursing homes focused on the implementation of intravenous therapy for single medications. The program was implemented in 2004 when no long term care facilities in the Syracuse area were providing this service.

The study data indicated that use of the Intravenous Medications Program declined from 72 patients in 2004, when the Program was implemented, to 39 - 40 patients between 2006 and 2012. Between 2004 and 2010, five of the area nursing homes implemented programs to provide single intravenous antibiotics. Most of this utilization involved intravenous vancomycin. By 2010, the Intravenous Medications Program had accomplished its objective. Only one nursing home was interested in continuing to receive Program Development Funds. Support from the Hospital Executive Council, including Program Development Funds, was eliminated in 2015.

The study data indicated that use of the High Cost Oral Medications Program increased from 65 patients in 2005, after the Program was implemented, to 134 patients in 2006. During this period, five area nursing homes implemented use of these medications with program support. After 2010, use of these medications were being used in the nursing homes without the need for the program. At that time, additional Program Development Funds were determined to be unnecessary. It was phased out and remaining medications were combined with the Enhanced Medications Program by 2012.

The Enhanced Medications Program was implemented in 2007 as a means of addressing remaining high cost intravenous and oral medications on a single patient basis. The Program was initiated based on more than 20 specific medications. All of these were specific to medication or medication and dosage. Between 2008 and 2015, use of most of these medications was implemented by area nursing homes without the Program. It was eliminated in 2016. Remaining intravenous medications were addressed by the Complex Care Program.

Table 1. Long term care subacute program utilization, Syracuse hospitals, 2004-2016.

\begin{tabular}{lccccccccc}
\hline & \multicolumn{8}{c}{ Number of Patients } & Total \\
& Jan-Dec & Jan-Dec & Jan-Dec & Jan-Dec & Jan-Dec & Jan-Dec & Jan-Jun & $\begin{array}{c}\text { Program } \\
\text { Development } \\
\text { Funds }\end{array}$ \\
\hline & 2004 & 2006 & 2008 & 2010 & 2012 & 2014 & 2016 & $\$ 228,750$ \\
IV Medications & 72 & 60 & 54 & 40 & 39 & 40 & - & $\$ 178,000$ \\
$\begin{array}{l}\text { High Cost Oral } \\
\text { Medications }\end{array}$ & 65 & 134 & 75 & 61 & 21 & - & 0 & \\
$\begin{array}{l}\text { Enhanced } \\
\text { Medications }\end{array}$ & - & - & 22 & 14 & 9 & 34 & 9 & $\$ 108,650$ \\
Wound Care & - & 18 & 9 & 7 & 7 & 19 & 2 & $\$ 124,000$ \\
Bariatric & - & - & 10 & 17 & 15 & 6 & 2 & $\$ 229,325$ \\
Off Site Services & - & - & 15 & 27 & 13 & 24 & 23 & $\$ 169,800$ \\
Total & 137 & 212 & 185 & 166 & 104 & 123 & 36 & $\$ 1,038,525$ \\
\hline
\end{tabular}

Source: Hospital Executive Council data. 
The Extensive Wound Care Program, focusing on the use of vacuum assisted closure device equipment in nursing homes, was implemented. The study data indicated the utilization of the Program ranged between 18 patients in 2006 and 19 patients in 2014. The original need for the program was based on high costs of the service associated with a single vendor as the provider. After 2012, the entry of additional vendors into the market reduced prices and the need for hospital support. It was eliminated in 2016.

The Subacute Bariatric Program was implemented in 2007 in order to stimulate the development of programs in nursing homes for patients with high Body Mass Indices discharged from hospitals. Program Development Funds were provided to 3 area nursing homes to support the acquisition of lifts, bariatric beds, wheelchairs, and other equipment for these patients, as well as for additional staff and training.

The study data indicated that, because of the limited scope of the program and the small number of nursing homes participating, utilization ranged from 10 patients in 2008 to 17 patients in 2010. By 2015, the participating nursing homes had implemented their own programs for care of bariatric patients and use of the Program was declining. It was eliminated in 2016.

The Patient Transportation Program, for stretcher and wheelchair transports, was implemented in 2007 to support the ability of area nursing homes to admit hospital patients who required transportation to offsite services. Most of these patients required dialysis that could be obtained at a number of area facilities. Most of the program population consisted of Medicare patients, for whom transportation was not a covered service. Medicaid patients were not included because Medicaid reimbursed the services directly to approved transport vendors.

The study data indicated that utilization of the Patient Transportation Program ranged from 13 to 27 patients between 2008 and 2016. Between January and June 2016, 24 patients used the program. Utilization of the Program has continued to justify its operation.

The study data also indicated that the Program Development Funds associated with each of the Subacute Programs ranged between $\$ 108,000$ and $\$ 229,000$ during their lifetimes. This amounted to approximately $\$ 20,000$ - $\$ 40,000$ per year for each program.

Data concerning the second component of the study, including utilization of the Complex Care Programs in the Syracuse area, are summarized in Table 2. Related information also includes descriptions of the implementation and operation of the programs.

The Complex Care Programs were developed by the Syracuse hospitals in 2015 as means of supporting long term acute care services that were beyond the scope of the Subacute Programs. They involved combinations of medications for patients in need of extended long term care services.

The Multiple Intravenous Medications Program was developed for hospital patients who required more than a single intravenous medication. In addition to the costs of the additional drugs, this need required nursing homes to increase staff beyond levels re- 
Table 2. Long term complex care program utilization, Syracuse hospitals, 2015-2016.

\begin{tabular}{|c|c|c|c|c|c|}
\hline & \multicolumn{4}{|c|}{ Number of Patients } & \multirow{2}{*}{$\begin{array}{c}\text { Total Program } \\
\text { Development } \\
\text { Funds }\end{array}$} \\
\hline & $\begin{array}{c}\text { January-June } \\
2015\end{array}$ & $\begin{array}{l}\text { July-December } \\
2015\end{array}$ & $\begin{array}{c}\text { January-June } \\
2016\end{array}$ & Total & \\
\hline $\begin{array}{l}\text { Multiple Intravenous } \\
\text { Medications }\end{array}$ & 15 & 10 & 3 & 28 & $\$ 78,400$ \\
\hline $\begin{array}{l}\text { Combination of } \\
\text { Medications }\end{array}$ & 4 & 0 & 5 & 9 & $\$ 27,000$ \\
\hline $\begin{array}{l}\text { Wound Care \& } \\
\text { Medications }\end{array}$ & 3 & 9 & 5 & 17 & $\$ 47,600$ \\
\hline Behavioral & 13 & 13 & 1 & 27 & $\$ 81,000$ \\
\hline Total & 35 & 32 & 14 & 81 & $\$ 234,000$ \\
\hline
\end{tabular}

Source: Hospital Executive Council.

quired for the original Intravenous Medication Program. Utilization of the Program was 15 patients for January-June 2015 and 10 patients for July-December 2015. Between January and June 2016, utilization declined to 3 patients.

The Combination of Medications Program was developed for hospital patients who required combinations of pharmaceuticals usually including oral and intravenous medications. This need required nursing homes to develop the capacity and the staff skills to administer and monitor these drugs. A number of pharmaceuticals addressed by the program had been included in the Enhanced Medications Program as single drugs. Utilization of the Program was 4 patients for January-June 2015, 0 patients for July-December 2015, and 5 patients for January-June 2016.

Utilization of the Multiple Intravenous Medications Program and the Combination of Medications Program did not meet anticipated volumes in the initial 18 months of operation. It was assumed that area nursing homes were developing the capacity to serve these populations. For this reason, the programs were combined in August 2016.

The Complex Wound Care Program was developed to address the needs of hospital patients who required wound care services plus intravenous medication. Utilization of the Program, like that of the other Complex Care services, was limited, ranging from 3 patients for January-June 2015 to 9 patients for July-December 2015. For this reason it was combined with the other Complex Care Programs in August 2016.

The Behavioral Care Program was developed to meet the needs of hospital patients who required 1 on 1 mental health care after discharge. It required substantial treatment planning by hospital and long term care staffs to implement this service in nursing homes. Utilization of the Program began with 13 patients for January-June 2015 and 13 patients for July-December 2015, but declined to one patient for January-June 2016.

It was determined that the decline in use of the Behavioral Care Program was related to the inability of the Program Development Funds it included to address the needs of most patients requiring 1 on 1 care in nursing homes. Available data suggested the funding that would be required to address these needs was beyond the scope of the 
Program. For this reason, it was eliminated in 2016.

The third component of the study focused on inpatient lengths of stay for adult medicine and adult surgery in the combined Syracuse hospitals during implementation of the Subacute and Complex Care Programs. Relevant data are summarized in Table 3.

This information suggested that the development and implementation of Subacute and Complex Care programs supported reductions in adult medicine hospital stays between 2014 and 2016 and reductions adult surgery stays between 2008 and 2016. They probably also limited the impact of the medical observation program on adult medicine stays.

This information demonstrated that mean lengths of stay for adult medicine in the combined hospitals increased from 4.98 to 5.45 days between 2008 and 2014 before declining to 5.20 days in 2016. The increase in adult medicine stays that occurred between 2012 and 2014 resulted from the implementation of medical observation regulations by Medicare in 2013. These regulations moved approximately 2,000 patients from the inpatient adult medicine population to outpatient observation. As a result, the remaining adult medicine stays increased.

The data demonstrated that, between 2008 and 2016, the adult medicine mean length of stay increased by 0.22 days, from 4.98 to 5.20 days. During the same period, the severity adjusted national average for the same population increased by 0.33 days, from 4.68 to 5.01 days.

The study data also demonstrated that mean lengths of stay for adult surgery declined from 6.23 to 5.94 days between 2008 and 2016. The medical observation regulations implemented by Medicare were not related to this service. During this period, the severity adjusted national average for this adult surgery population increased by 0.49 days, from 5.63 to 6.12 days.

Table 3. Inpatient Mean Lengths of Stay, Adult Medicine and Adult Surgery, Syracuse Hospitals, 2008, 2010, 2012, 2014, 2016.

\begin{tabular}{lccccc}
\hline & 2008 & 2010 & 2012 & 2014 & $2016^{*}$ \\
\hline Adult Medicine & & & & & \\
Number of Discharges & 28,565 & 32,221 & 35,274 & 33,421 & 11,259 \\
Mean Length of Stay & 4.98 & 5.18 & 5.14 & 5.45 & 5.20 \\
Severity Adjusted National Average & 4.68 & 4.84 & 5.00 & 5.20 & 5.01 \\
Adult Surgery & & & & & \\
Number of Discharges & 19,241 & 19,170 & 20,439 & 20,562 & 7,554 \\
Mean Length of Stay & 6.23 & 6.25 & 6.04 & 6.04 & 5.94 \\
Severity Adjusted National Average & 5.63 & 5.89 & 5.75 & 5.95 & 6.12 \\
\hline
\end{tabular}

*2016 data are for January-June. Adult medicine data exclude Diagnosis Related Groups concerning surgery, obstetrics, pediatrics, psychiatry, alcohol/substance abuse treatment, rehabilitation, and all patients aged $0-17$ years. Adult surgery data exclude Diagnosis Related Groups concerning medicine, obstetrics, pediatrics, psychiatry, alcohol/substance abuse treatment, and all patients aged 0 - 17 years. Source: Hospital Executive Council. 


\section{Discussion}

Patients who require subacute and complex care services have been a challenge for hospitals attempting to reduce inpatient stays and improve efficiency. These patients need the continuing services that they received in acute care but in residential settings. These services are frequently not available in rehabilitation or skilled nursing facilities. In recent years, increases in numbers of high severity of illness patients in hospitals have added to this challenge.

Nursing care managers have a major responsibility in supporting the care of these patients. This includes the development of programs and assuring that the needs of individual patients are met. Increasing numbers of elderly patients do not have family or friends to assist as care providers. Care for them must be arranged in rehabilitation or skilled nursing facilities.

In the United States, some states have implemented long term acute care programs which add another level of care to serve the needs of these patients. The Medicaid expenses related to these services have limited the use of these programs. In many communities, which do not have access to these programs, acute hospitals have had to develop their own programs with nursing homes and other providers.

This study described the efforts of hospitals in Syracuse, New York, a small metropolitan area, to develop services for subacute and complex care patients using their own resources in cooperation with local nursing homes. The clinical content of these services, including high cost medications, intravenous therapy, extensive wound care, and bariatric care made their delivery in settings where they had not been available a considerable challenge. In the absence of third party reimbursement for another level of care, the hospitals provided Program Development Funds for limited time periods in order to initiate these services.

The study data suggested that most of these efforts in Syracuse were successful in implementing these programs in nursing homes. Hospital resources helped support the development of intravenous therapy, the use of high cost medications, extensive wound care, and bariatric services in nursing homes where none existed previously.

Of equal or greater importance was the manner in which the Syracuse hospitals were able to phase out support for these services after they were operational for extended periods of time. This process suggested that the participating nursing homes had a genuine interest in the provision of these forms of care and in the development of their own resources to support them.

Although it was difficult to separate the impact of these initiatives from other efforts, the study data indicated that their implementation in Syracuse long term care facilities contributed to a lower rate of increase in adult medicine lengths of stay and a reduction in adult surgery lengths of stay in the Syracuse hospitals between 2008 and 2016. During this period, the severity of illness of patients in both major services increased in the combined hospitals.

The planning and development of the Subacute and Complex Care Programs in Syracuse was not an overly complicated process. It did, however, require both acute and 
long term care providers who were interested in making the process work for the benefit of the patient populations involved, as well as for the needs of their own organizations. The work of the Hospital Executive Council was also useful in carrying out the planning process and in maintaining consistency in distribution of program development funds according to the standards set.

As they face the future, nursing care managers need to prepare for continuing changes in how and where medical services are provided, as well as how those services are reimbursed. They need to look at alternative settings and professional preparation needed to offer long term acute services for the population that requires them.

Implementation of programs like the Subacute and Complex Care Programs demonstrate that competing organizations can work together to provide needed services to those they serve. Transitioning patients appropriately benefits all, providing quality care at lower cost and improving access to care in the community.

\section{References}

[1] Dentzler, S. (2011) Urgent Measures for an Old Problem. Health Affairs, 30, 1626. http://dx.doi.org/10.1377/hlthaff.2011.0961

[2] Keehan, S.P., Cuckler, G.A., Sisko, A.M., Madison, A.J., Smith, S.D., Stone, D.A., Poisal, J.A., Wolfe, C.J. and Lizonitz JM. (2015) National Health Expenditure Projections, 20142024: Spending Growth Faster than Recent Trends. Health Affairs, 34, 1407-1417.

[3] Lizonitz, J.M. (2015) National Health Expenditure Projections, 2014-24: Spending Growth Faster than Recent Trends. Health Affairs, 34, 1407-1417.

http://dx.doi.org/10.1377/hlthaff.2015.0600

[4] Riley, G.F. (2007) Long Term Trends in the Concentration of Medicare Spending. Health Affairs, 26, 808-814. http://dx.doi.org/10.1377/hlthaff.26.3.808

[5] Evans, M. (2012) The Early Returns on Accountable Care. Modern Healthcare, 42, S1-S5.

[6] Joynt, K.E., Gawande, A.A., Orav, E.J. and Jha, A.K. (2013) Contribution of Preventable Acute Care Spending to Total Spending for High Cost Medicare Patients. JAMA, 309, 2572-2578. http://dx.doi.org/10.1001/jama.2013.7103

[7] Muchmore, S. (2016) Few Docs Ready for Risk. Modern Healthcare, 46, 20-22.

[8] Whitman, E. (2016) Bundled Payment Expansion Brings Providers More Risk and Opportunity. Modern Healthcare, 46, 8-10.

[9] Weil, A.R. (2015) Hospital Costs and Quality. Health Affairs, 34, 1263. http://dx.doi.org/10.1377/hlthaff.2015.0786

[10] Skinner, J., Chandra, A., Goodman, D. and Fisher, E.S. (2009) The Elusive Connection between Health Care Spending and Quality. Health Affairs, 28, w119-w123. http://dx.doi.org/10.1377/hlthaff.28.1.w119

[11] Rau, J. (2014) Medicare Fines 2610 Hospitals in Third Round of Readmission Penalties. Kaiser Health News.

[12] Berenson, R.A., Paulus, R.A. and Kalman, N.S. (2012) Medicare's Readmission Reduction Program-A Positive Alternative. New England Journal of Medicine, 366, 1364-1366. http://dx.doi.org/10.1056/NEJMp1201268

[13] Gawande, A.A. (2011) The Hot Spotters: Can We Lower Costs by Giving the Neediest Patients Better Care? New York. 
[14] Hong, C.S., Siegel, A.L. and Ferris, T.G. (2014) Caring for High Need, High Cost Patients: What Makes for a Successful Care Management Program? Commonwealth Fund, New York. http://dx.doi.org/10.15868/socialsector.25007

[15] Lagoe, R., Pasinski, T., Kronenberg P., Quinn, T. and Schaengold, P. (2005) Linking Health Services at the Community Level. Canada Health Care Quarterly, 9, 60-65.

[16] Lagoe, R., Pernisi, L. and Littau, S. (2015) Reducing Hospital Stays through Subacute and Complex Care Programs. Open Journal of Nursing, 5, 848-854.

http://dx.doi.org/10.4236/ojn.2015.510090

Submit or recommend next manuscript to SCIRP and we will provide best service for you:

Accepting pre-submission inquiries through Email, Facebook, LinkedIn, Twitter, etc. A wide selection of journals (inclusive of 9 subjects, more than 200 journals)

Providing 24-hour high-quality service

User-friendly online submission system

Fair and swift peer-review system

Efficient typesetting and proofreading procedure

Display of the result of downloads and visits, as well as the number of cited articles Maximum dissemination of your research work

Submit your manuscript at: http://papersubmission.scirp.org/

Or contact ojn@scirp.org 